\title{
A comparison of perceptions of nuts between the general public, dietitians, general practitioners, and nurses
}

\author{
Rachel Clare Brown ${ }^{\text {Corresp., }}{ }^{1}$ ， Andrew Robert Gray ${ }^{2}$, Lee Ching Yong ${ }^{1}$ ， Alex Chisholm ${ }^{1}$, Sook Ling Leong ${ }^{1}$, \\ Siew Ling Tey ${ }^{1}$ \\ 1 Department of Human Nutrition, University of Otago, Dunedin, New Zealand \\ 2 Biostatistics Unit, Dean's Office, Dunedin School of Medicine, University of Otago, Dunedin, New Zealand \\ Corresponding Author: Rachel Clare Brown \\ Email address: rachel.brown@otago.ac.nz
}

Background. Nut consumption at the population level remains low despite the welldocumented benefits of their consumption, including their cardioprotective effects. Studies have suggested that advice from health professionals may be a means to increase nut consumption levels. Understanding how nuts are perceived by the public and health professionals, as along with understanding the public's perceptions of motivators of and deterrents to consuming nuts, may inform the development of initiatives to improve on these low levels of consumption. The aim of this cross-sectional study was to compare perceptions of nuts among three groups of health professionals (dietitians, general practioners, and practice nurses) and the general public in New Zealand (NZ), along with motivators of and deterrents to consuming nuts amongst the general public and their experiences of receiving advice around nut consumption. Methods. The NZ Electoral roll was used to identify dietitians, general practitioners (GPs), and practice nurses, based on their free-text occupation descriptions, who were then invited to complete a questionnaire with 318, 292, and 149 respondents respectively. 1600 members of the general public were randomly selected from the roll with 710 respondents. Analyses were performed using Chi-squared tests to look at differences in categorical variables and linear regression for differences in other variables between the four survey groups. Results. Although there were significant differences between the four groups regarding the perceptions of nuts, in general there was agreement that nuts are healthy, high in protein and fat, are filling, and some nuts are high in selenium. We noted frequent agreement that the general public participants would consume more if nuts: improved health (67\%), were more affordable $(60 \%)$, or improved the nutrient content $(59 \%)$ and balance of fats $(58 \%)$ within their diets. Over half the respondents reported they would eat more nuts if they were advised to do so by a dietitian or doctor, despite less than $4 \%$ reporting they had received such advice. The most frequently selected deterrents to increasing nut consumption were: cost $(67 \%)$, 
potential weight gain (66\%), and leading to eating too much fat (63\%). Discussion. It is concerning that so few among the general public report receiving advice to consume more nuts from health professionals, especially given their apparent responsiveness to such advice. Health professionals could exploit the motivators of nut consumption, while also addressing the deterrents, to promote nut intake. These factors should also be addressed in public health messages to encourage regular nut consumption among the public. Educational initiatives could also be used to improve the nutritional knowledge of GPs and practice nurses with regard to nuts, although even dietitians were unsure of their knowledge in some cases. 
1 A comparison of perceptions of nuts between the general public, dietitians, general practitioners, 2 and nurses

3

4 Rachel Clare Brown ${ }^{1 *}$, Andrew Robert Gray ${ }^{2}$, Lee Ching Yong ${ }^{1}$, Alex Chisholm¹, Sook Ling 5 Leong ${ }^{1}$, Siew Ling Tey ${ }^{1}$

6

$7 \quad{ }^{1}$ Department of Human Nutrition, University of Otago, Dunedin, New Zealand

8 2Biostatistics Unit, Dean's Office, Dunedin School of Medicine, University of Otago, Dunedin, 9 New Zealand

10

11

$12 *$ Corresponding author:

13 Dr Rachel Brown

14700 Cumberland Street, Dunedin 9052, New Zealand

15 Email: rachel.brown@otago.ac.nz

16

17

18

19 
20 Abstract

21 Background. Nut consumption at the population level remains low despite the well-documented 22 benefits of their consumption, including their cardioprotective effects. Studies have suggested 23 that advice from health professionals may be a means to increase nut consumption levels. 24 Understanding how the public and health professionals perceive nuts, along with understanding 25 what motivates the public to consume nuts and what deters them, may inform the development of initiatives to improve on these low levels of consumption. The aim of this cross-sectional study was to compare perceptions of nuts among three groups of health professionals (dietitians, general practitioners, and practice nurses) and the general public in New Zealand (NZ), along with motivators of and deterrents to consuming nuts amongst the general public and their experiences of receiving advice around nut consumption.

31 Methods. The NZ Electoral roll was used to identify dietitians, general practitioners (GPs), and 32 practice nurses $(n=1440)$, based on their free-text occupation descriptions, who were then invited 33 to complete a questionnaire with 318,292 , and 149 respondents respectively. 1600 members of 34 the general public were randomly selected from the roll with 710 respondents. Analyses were 35 performed using Chi-squared tests to look at differences in categorical variables and linear regression for differences in other variables between the four survey groups.

37 Results. Although there were significant differences between the four groups regarding the perceptions of nuts, in general there was agreement that nuts are healthy, high in protein and fat, are filling, and some nuts are high in selenium. We noted frequent agreement that the general public participants would consume more nuts if nuts: improved health $(67 \%)$, were more affordable $(60 \%)$, or improved the nutrient content (59\%) and balance of fats $(58 \%)$ within their diets. Over half the respondents reported they would eat more nuts if they were advised to do so

43 by a dietitian or doctor, despite less than $4 \%$ reporting they had received such advice. The most 44 frequently selected deterrents to increasing nut consumption were: cost (67\%), potential weight gain $(66 \%)$, and leading to eating too much fat $(63 \%)$.

46 Discussion. It is concerning that so few among the general public report receiving advice from 47 health professionals to consume more nuts, especially given their apparent responsiveness to such advice. Health professionals could exploit the motivators of nut consumption, while also addressing the deterrents, to promote nut intake. These factors should be addressed particularly 
51 initiatives could also be used to improve the nutritional knowledge of GPs and practice nurses 52 with regard to nuts, although even dietitians were unsure of their knowledge in some cases. 


\section{Introduction}

54 Nuts have been part of the human diet since paleothic times (Salas-Salvado et al. 2011), 55 providing rich sources of cis-unsaturated fats, fibre, and a number of phytochemicals (Alasalvar 56 \& Bolling 2015; Brufau et al. 2006; Ros 2010). Although specific types of nuts differ in their 57 micronutrient content, as a food group they can provide substantial amounts of vitamin E, folate, 58 calcium, copper, magnesium, potassium, and selenium to the diet (O'Neil et al. 2010; O'Neil et 59 al. 2015). The regular consumption of nuts is associated with lower total mortality (Grosso et al. 60 2015; Hshieh et al. 2015). This reduction is largely due to a lower risk of cardiovascular disease 61 (Guasch-Ferre et al. 2017; Kris-Etherton et al. 1999; Nash \& Nash 2008; Ros 2010; Ros et al. 62 2010; Sabate et al. 2010). The regular consumption of nuts has also been associated with 63 reductions in certain cancers including colorectal, endometrial, gastric, lung, and pancreatic 64 (Aune et al. 2016; Bao et al. 2013a; Bao et al. 2013b; Fadelu et al. 2018; Hashemian et al. 2017; 65 Lee et al. 2018; Lee et al. 2017; van den Brandt \& Nieuwenhuis 2018; Wu et al. 2015). Although 66 nut consumption has been negatively associated with the incidence of diabetes (Afshin et al. 67 2014), these findings are not consistent across studies (Hshieh et al. 2015; Luo et al. 2014; Zhou 68 et al. 2014). A number of epidemiological studies have examined the association between 69 cognitive function and dietary patterns that are characterised by high intakes of nuts, including 70 the Mediterranean and Dietary Approaches to Stop Hypertension (DASH) diets (Katsiardanis et 71 al. 2013; Samieri et al. 2013; Valls-Pedret et al. 2012; Wengreen et al. 2013). On the whole, 72 these studies show better cognitive function among those adherent to these dietary patterns. 73 Several mechanisms appear to be implicated in the protective role of nuts, including antioxidant 74 and anti-inflammatory properties, largely related to their nutrient composition, in particular their 75 cis-unsaturated fat, vitamin, and polyphenol content (Grosso \& Estruch 2016).

76 Although the cardioprotective effects of nuts have been widely established, the population 77 intake of nuts has been reported as far from optimal in a number of countries (Brown et al. 2014; 78 Jenab et al. 2006; O'Neil et al. 2012; O'Neil et al. 2015). For example, in New Zealand (NZ), 79 Europe, and the United States of America (USA) less than 8\% of the population on a given day 80 consumed whole nuts (Brown et al. 2014; Jenab et al. 2006; O'Neil et al. 2012; O'Neil et al. 81 2015). In addition, the mean population intake of whole nuts is low at less than $3.5 \mathrm{~g} / \mathrm{d}$. Given 82 that dietary guidelines recommended daily nut intakes of 30 to $42 \mathrm{~g} / \mathrm{d}$ (Tey et al. 2012; US Food 
83 and Drug Administration 2003), it is apparent that strategies to increase regular nut consumption

84 at the population level are needed.

85 Two studies have suggested that individuals would increase their nut intake if they were advised

86 to do so by their doctor (Pawlak et al. 2009; Pawlak et al. 2012). Thus, it appears that health

87 professionals may be important facilitators of nut intake. However, despite this willingness to

88 increase nut intake, in both these studies, which included those with or at risk of CVD and/or

89 diabetes (Pawlak et al. 2012), or those on a low income (Pawlak et al. 2009), there was general

90 agreement among participants that eating nuts on most days of the week would not be consistent

91 with the advice of their doctor. Therefore, it is important to gain an understanding on how health

92 professionals perceive nuts, and how this may influence their advice to consume nuts.

93 Comparison with the general public could assess whether there are any disparities regarding

94 perceptions of nuts which may affect recommendations and nut intakes respectively. In addition,

95 gaining information from the general public on the motivation of and deterrents to nut

96 consumption may provide important information for health professionals to use in practice in

97 order to increase regular nut consumption among their patients and clients.

98 Therefore, this study aimed to examine the beliefs, attitudes and perceptions of nuts among

99 health professionals and a cross-section of the general public in New Zealand. In addition we

100 aimed to determine the conditional motivators of and deterrents to regular nut consumption

101 among the general population.

102

103 Materials \& Methods

104 The study methods are described in detail elsewhere (Brown et al. 2017; Yong et al. 2017), and 105 only essential details are presented here.

106

107 Study design and participants

108 This was a cross-sectional study, comprising two surveys; one sent to members of the general 109 public and the other to selected health professionals. The general public participants were a 110 national sample of NZ adults aged 18 years and over. Overall, 1600 participants were randomly 111 selected from the NZ electoral rolls. All NZ citizens and permanent residents aged 18 years or 112 older are required to be registered on the Parliamentary Electoral Roll. It is estimated that the roll 113 includes 92.6\% of all adults (Electoral Commission 2014). Oversampling of Māori (the 
114 indigenous people of New Zealand) was used to achieve sufficient numbers for analyses

115 involving this ethnic group.

116 Health professionals were identified from the NZ Electoral Roll, which included self-described

117 occupations. We identified individuals whose occupation fell under three main categories:

118 dietitians $(\mathrm{n}=578)$, general practitioners (GPs) $(\mathrm{n}=596)$, and practice nurses $(\mathrm{n}=266)$. These

119 professions reflect those who we considered the most likely to provide dietary advice.

120 An information sheet was sent to all participants, and completion of the survey was taken as

121 informed consent. The study was approved by the University of Otago Ethics Committee

122 (reference number D14/288).

123

124 Survey development

125 Two different self-administered questionnaires were developed, one for the general public and 126 one for health professionals. The questionnaires used multiple response questions. Both

127 questionnaires contained questions on socio-demographic characteristics, and assessed

128 perceptions and knowledge of nuts (including nut butter). The general public questionnaire asked

129 about previous advice from health professionals regarding nut consumption, and conditional

130 motivators and deterrents to eating nuts. They were also asked about their intention to eat nuts in

131 the future. The health professional's questionnaire asked the reasons given by their patients for 132 not eating nuts.

133 Both questionnaires were developed by a group of researchers with expertise in the area of nuts 134 and health, and were pre-tested and modified where appropriate to establish both face and 135 content validity. The general public questionnaire was pretested among a group of 43 members 136 of the general public, whereas the health professional's questionnaire was pretested among six 137 dietitians, two general practitioners, and four practice nurses.

138

139 Survey administration

140 Both an online version (Survey Gizmo $($ C (Widgix Software, LLC, Colorado, USA) and a paper 141 copy of the questionnaire were available. A modified version of Dillman's four-stage tailored 142 design method (Dillman 2011) was used for recruitment for both questionnaires. Firstly, an 143 invitation to participate and the URL for the survey were mailed to participants. This was 144 followed seven days later by a postcard thanking those who had already responded and 
145 reminding those who had not. After another eight days, a paper version of the questionnaire was

146 sent to the remaining non-respondents. Lastly, a second postcard was sent to recipients of the

147 third mail-out another twelve days later thanking those who had responded and reminding those

148 who had not. Users were provided with an online login code so that each participant could only

149 complete the questionnaire once. Also, each paper questionnaire had a unique code to prevent

150 duplication.

151

152 Statistical analysis

153 As some respondents to the general public component were health professionals themselves, we 154 removed all those from the sample and respondents who identified as any type of doctor or nurse 155 as well as pharmacists, acupuncturist, dentists, dental nurses and assistants, orthodontists, 156 naturopaths, physiologists, physiotherapists, midwives, veterinarians, and other healthcare 157 workers who would have contact with patients, but not laboratory technicians, or medical 158 secretaries and receptionists.

159 Appropriate descriptive statistics were calculated for all variables of interest (means and standard 160 deviations for approximately normally-distributed Likert-type scale items and other continuous 161 variables, medians and interquartile ranges for other ordinal and continuous variables, and 162 frequencies and percentages for categorical variables). Chi-squared tests of homogeneity were 163 used to compare the proportion responding "do no know" to each of the 15 belief and perception 164 questions between the four groups (dietitians, GPs, practice nurses, and the general public). 165 Linear regression models were then used to compare the means of the Likert-type responses to 166 the same 15 questions between the four groups, both without and with adjustment for age, sex, 167 ethnicity, education, and employment. Model diagnostics included inspecting histograms of 168 model residuals for approximate normality and scatter plots of model residuals against fitted 169 values and continuous predictors for a lack of evidence of homoscedasticity or non-linearity. All 170 statistical analyses were performed using Stata 14.2 and, two-sided when available, $\mathrm{p}<0.05$ was 171 considered statistically significant.

172

173 Results

174 Response rates 
175 The response rate for the full general population sample was $44 \%(n=710)$, and for this sample

176 with the health professionals removed was $43 \%(n=668)$. The response rate was $53 \%(n=759)$ for

177 the health professionals.

178

179 Participant characteristics

180 The characteristics of survey respondents are presented in Table 1. The majority of dietitians 181 (97\%) and practice nurses (96\%) were females, whereas just over half of the general 182 practitioners and general public were females. The mean age of dietitians was around 8 years 183 younger than the other groups, where the mean ages ranged from 51 to 53 years. Most of the 184 participants were NZ European, especially in the health professional groups (ranging from $82 \%$ 185 to $89 \%$ ) compared to the general public (70\%). The health professional respondents had a 186 median of 20 years as registered practitioners, with practice nurses having being registered 5 and 18712 years longer than GPs and dietitians respectively.

188

189 Previous advice to eat nuts by health professionals

190 Table 2 shows the percentage of the general population respondents who have previously 191 received advice from a health professional regarding nut consumption. The majority of 192 participants $(84 \%, \mathrm{n}=596)$ reported that they have never received advice from any health 193 professional regarding nut consumption. Only $3.8 \%(n=27), 2.8 \%(n=20)$ and $1.1 \%(n=8)$

194 reported receiving advice to eat more nuts or nut butters from a dietitian, GP, or practice nurse 195 respectively, with $7.2 \%(n=51)$ receiving advice from at least one of these groups. Even fewer 196 participants were asked to eat fewer nuts or nut butters, or to maintain their level of consumption 197 by a health professional.

198

199 Intention by the general public to eat nuts in the future

200 The general public were asked if they would like to increase, decrease, or not change their nut 201 intake. Overall, 73\% $(n=520)$ reported they did not want to change the amount they ate, whereas $20222 \%(n=159)$ reported they would like to increase their nut intake. Only $3 \%(n=24)$ reported that 203 they would like to eat fewer nuts.

204

205 Reasons patients give health professionals for not eating nuts 
206 Health professionals were asked to report reasons given by their patients for not eating nuts. The 207 most common reasons were "they are too expensive" $(34 \%, n=260)$, "they are allergic to nuts" $208(26 \%, n=200)$, "they have dental issues" $(22 \%, n=169)$, "eating nuts can cause weight gain" $209(21 \%, n=156)$, and "nuts are high in calories" $(18 \%, n=130)$ with $24 \%(n=184)$ indicating either 210 weight gain or calories.

211

212 Conditional motivation to eat more nuts or nut butters by general public

213 Table 3 shows the responses from the general public regarding potential motivators for eating 214 nuts. The four motivators with the most agreement included "make me healthier", "more 215 affordable", "help me get more nutrients", and "help me get the right balance of fats". Over half 216 of participants agreed or strongly agreed they would eat more nuts if they were advised to so by a 217 dietitian $(54 \%, \mathrm{n}=350)$ or a doctor $(53 \%, \mathrm{n}=344)$.

218

219 Conditional deterrents to eating nuts or nut butters

220 Table 4 shows the responses to questions regarding potential deterrents to eating more nuts or 221 nut butters. The most strongly endorsed deterrent was "if eating them would cost me too much 222 money". This was followed by "if eating them would cause me to gain weight", and "if eating 223 them would cause me to eat too much fat".

224

\section{Perceptions and knowledge of nuts}

226 Table 5 shows the mean response from the scale of strongly agree $=1$ to strongly disagree $=5$, for 227 perceptions of nuts for non-health professional general public and health professionals. Although 228 there were statistically significant differences between the four groups regarding the perceptions 229 of nuts (all $\mathrm{P}<0.001$ ), in general there was agreement that nuts are healthy (mean: 1.7-2.1), high 230 in protein (mean: 1.8-2.1) and fat (mean: 1.7-2.4), are filling (mean: 1.9-2.2), and some nuts are 231 high in selenium (mean: 1.6-2.2). In general, the four groups disagreed with the perceptions that 232 nuts are low in energy (mean: 3.5-4.5), vitamins and minerals (mean: 3.5-4.2), and that eating 233 nuts can increase people's risk of CVD (mean: 3.4-4.3).

234 There was evidence for a statistically significant difference between groups for all perceptions 235 (all $\mathrm{P} \leq 0.013$ for unadjusted and adjusted models), except for "eating them can help lower 236 people's risk of diabetes" and "Eating them will cause people to gain weight", with the latter 
237 significant only in the unadjusted model. For all other questions, the responses of dietitians

238 differed statistically significantly from the general public without and with adjustment for age,

239 sex, ethnicity, education, and employment status.

240 Table 6 shows the percentage of health professionals and the non-health professional general

241 public $(n=668)$ who responded 'I do not know' to perception statements regarding nuts. The

242 statements which received the highest responses for this were regarding "eating them can help

243 lower people's risk of diabetes" (10-54\%), "some of them are high in selenium" (2-45\%), "eating

244 them can increase people's total blood cholesterol" (2-43\%), "some nuts are high in iron" (2-

$24543 \%$ ), and "they are high in antioxidants" (6-39\%). There was evidence of a statistically

246 significant difference between the four groups (three health professional and the general public)

247 for each of the perceptions (all $\mathrm{P}<0.001$ ). Overall, dietitians were least likely to indicate a lack of

248 knowledge, whereas the general public were most likely to respond "I do not know". Both GPs

249 and practice nurses tended to be intermediary in their responses.

250 The statements that health professionals were most unsure of included "some of them are high in 251 iron" (11-25\%) and "eating them can help lower people's risk of diabetes" (10-16\%). However, 252 as in the general trend for the other perceptions, the percentage of the general public responding 253 "I do not know" to these two statements was statistically significantly higher than the three 254 health professions, and significantly more GPs and practice nurses were likely to respond in this 255 way compared to dietitians.

256

\section{Discussion}

258 To the best of our knowledge, this is the first study to investigate motivators of, and deterrents to, 259 nut intake among the general population, and to compare the perceptions of nuts between the 260 general public and health professionals. Very few general public respondents reported receiving 261 advice to eat nuts regularly from health professionals.

262 In general, there was agreement among the groups for the perceptions that nuts are healthy, high 263 in protein and fat, are filling, and some nuts are high in selenium. There was an overall pattern of 264 higher agreement amongst dietitians, followed by GPs and practice nurses, with the lowest level 265 of agreement among the general public. There appeared to be some confusion among groups 266 regarding the effects of nut consumption on diabetes risk and weight gain. 
267 It is concerning that less than $4 \%$ of the general public had previously been advised to eat more 268 nuts by a dietitian, GP or practice nurse. This seems especially low given that there was strong 269 agreement among health professionals that nuts are healthy. Also, it appears that the general 270 public would be responsive to such advice, given that over $50 \%$ of participants reported that they 271 would eat more nuts if advised to do so by a dietitian or a doctor. These findings are consistent 272 with those of Pawlak et al. who reported strong agreement among their low-income participants 273 that they would eat nuts if advised to do so by their doctor (Pawlak et al. 2009). Also, among a 274 cohort with or at risk of CVD and/or diabetes, $63 \%$ of participants claimed they would eat nuts 275 on most days of the week if this was recommended by their doctor (Pawlak et al. 2012). In both 276 these studies, participants did not generally agree that eating nuts on most days of the week was 277 consistent with advice from their doctor. Collectively, the results from the present study and 278 those by Pawlak et al. suggest that the general public are not receiving advice to eat nuts 279 regularly by health professionals, but many would do so, if they received such advice. Therefore, 280 health professionals are potentially important facilitators of regular nut consumption.

281 In order to increase population intakes of nuts, it is useful for health professionals to understand 282 what would motivate their patients to eat more nuts, and what might deter them. These barriers 283 and facilitators also provide useful information for designing public health messages aimed at 284 increasing nut intake. The most popular motivators to eat more nuts were largely related to health 285 outcomes e.g."would help me feel healthier" and "would help me get more nutrients". This 286 indicates that people are largely interested in their health. Therefore, highlighting the health 287 benefits of eating nuts on a regular basis is important. This information should be included in 288 promotion material encouraging nut consumption.

289 The top deterrent to eating more nuts was "if they cost too much". This is congruent with the 290 second most prevalent motivator, which indicated people would eat more if they were more 291 affordable. Further to this, 34\% of health professionals reported that their patients did not eat 292 nuts because they considered them to be too expensive. Nuts range in price in NZ (1US dollar = 293 1.48NZ dollar) from around NZ\$0.21 (peanuts) to NZ\$2.37 (pine nuts) per $30 \mathrm{~g}$ serve. The less 294 expensive types are peanuts, almonds, and cashew nuts. Peanut butter is also an affordable form 295 at around NZ\$0.36 per $30 \mathrm{~g}$ serve. Therefore, these types of nuts, especially in forms with no 296 added sugar, salt, and oil, could be promoted as the most affordable, especially to those on a low 297 income. In addition, it is important to put the price of nuts into context with other snacks where 
298 they compare favourably to fruit (e.g. one banana NZ\$0.70), cereal bars (around NZ\$0.50 per 299 bar), and potato crisps (around NZ\$1.49 per 40 g packet).

300 Other deterrents to nut consumption included if they "cause me to eat too much fat", "cause me 301 to gain weight, and "cause me to eat too many calories". These latter two were also reasons that 302 around one-fifth of patients gave to health professionals for not eating nuts. It therefore appears 303 that some of the general public are worried about weight gain. Nuts are energy-dense and high in 304 fat. However, epidemiological research suggests that regular nut consumers are leaner than non305 nut consumers (Bes-Rastrollo et al. 2007; Bes-Rastrollo et al. 2009; Martinez-Gonzalez \& Bes306 Rastrollo 2011; Mozaffarian et al. 2011). Also, intervention studies have shown that the addition 307 of nuts to the regular diet results in no weight gain, or less weight gain than predicted (based on 308 the extra energy from the nuts) (Alper \& Mattes 2002; Flores-Mateo et al. 2013; Hollis \& Mattes 309 2007; Mattes et al. 2008; Tey et al. 2011). Suggested mechanisms for this finding include 310 increased satiety (Brennan et al. 2010; Mattes 2008; Tan \& Mattes 2013) increased metabolic 311 rate (Alper \& Mattes 2002; Claesson et al. 2009; Coelho et al. 2006), and increased loss of 312 metabolisable energy in the faeces (Ellis et al. 2004; Gebauer et al. 2016; Grundy et al. 2015; 313 Grundy et al. 2016; Novotny et al. 2012). Given that the fear of weight gain may be deterring 314 some people from consuming nuts on a regular basis, nut-promoting messages should include 315 information from the wealth of research suggesting that adding nuts to the diet does not result in 316 weight gain, especially when nuts are used to replace other less healthful snacks. In addition, it is 317 likely that there needs to be more education aimed at health professionals in this area, given the 318 majority of these participants seemed unsure about the potential of nuts to cause weight gain. In 319 fact, around 10\% of dietitians and around one-fifth of GPs and practice nurses agreed that eating 320 nuts caused weight gain. Thus targeted education on this topic needed improve the advice given 321 to patients.

322 A further barrier to regular nut consumption highlighted by the current research was dentition 323 issues. Over one-quarter of health professionals reported that their patients did not wish to eat 324 nuts because of dental issues. An alternative to eating whole nuts is to incorporate nut butters 325 into the diet. It seems intuitive that nut butters should provide health benefits similar to those 326 seen with whole nuts. However, few studies have investigated whether the benefits of whole nuts 327 can be extrapolated to nut butters. Two recent epidemiological studies (Luu et al. 2015; van den 328 Brandt \& Schouten 2015) reported significantly lower total mortality with increased nut intake, 
329 but not nut butter alone. Conversely, the Nurses' Health Study (NHS) showed peanut butter 330 consumption was inversely associated with type 2 diabetes in women (Jiang et al. 2002) and in a 331 subset including women with type 2 diabetes, cardiovascular risk was significantly lower among 332 those consuming peanuts and peanut butter at least five times per week (Li et al. 2009). Two 333 interventions found significant improvements in blood lipids after consuming different forms of 334 peanuts or almonds (including butter), with no significant differences between groups 335 (McKiernan et al. 2010; Spiller et al. 2003). While promising, these studies had short 336 intervention periods (28 days) and were possibly underpowered. Longer, adequately-powered 337 studies are required in order to develop firm conclusions. One potentially important difference 338 between nuts and nut butters is the effects on energy balance. As mentioned previously, studies 339 examining body weight (Alper \& Mattes 2002; Fraser et al. 2002; Hollis \& Mattes 2007; Sabate 340 et al. 2005; Tey et al. 2011) indicate eating whole nuts results in less weight gain than predicted, 341 possibly through increased satiety (Mattes 2008). The effect of nut butters on weight and satiety 342 needs clarification. Also, a recent study reported the measured metabolisable energy of whole 343 almonds (4.42 kcal/g) and almond butter $(6.53 \mathrm{kcal} / \mathrm{g})$ differed significantly (Gebauer et al. 344 2016), and thus may have differing effects on energy intake and body weight regulation 345 (Gebauer et al. 2016; Grundy et al. 2016). Therefore, given there is surprisingly little information 346 on the health benefits of consuming nut butter, it is an important area for future research, so that 347 evidence-based guidelines can be developed.

348 It is of interest to compare the perceptions of nuts between health professionals and the general 349 public to examine if there are major disparities, which need to be addressed so that there is a 350 consistent understanding of the health benefits of regular nut consumption. For the statements 351 regarding the perceptions of nuts, dietitians were least likely to respond that they "did not know", 352 while the general public were mostly likely to, with the GPs and practice nurses intermediary. 353 There was a similar pattern when analysing agreement and disagreement for the perceptions. 354 Among the top 5 perceptions to which participants, especially the general public, were most 355 likely to respond "I don't know", were "eating them can increase people's total blood 356 cholesterol", "they are high in antioxidants", "some of them are high in selenium", "some of 357 them are high in iron", and "eating them can help lower people's risk of diabetes". It is not 358 surprising the latter statement received a high prevalence of "I don't know" responses as there is 359 conflicting evidence regarding this in the scientific literature. While one meta-analysis reported a 
360 small but significant decrease in the incidence of type 2 diabetes, this study has been criticised

361 on the basis of study selection (one study did not examine the independent effects of nuts), and

362 failure to adjust for BMI (Afshin et al. 2014). Conversely, two other meta-analyses have reported

363 no association between nut consumption and the risk of developing type 2 diabetes (Luo et al.

364 2014; Zhou et al. 2014). There was also confusion regarding the iron content of nuts. Some nuts

365 can be useful sources of iron, but this will be in the form of non-haeme iron, which is less

366 absorbable and can be influenced by other components of the diets. Also, despite the high

367 prevalence of "I don't know" responses, it is well established that nuts have

368 hypocholesterolaemic properties (Musa-Veloso et al. 2016; Sabate et al. 2010), are rich sources

369 of antioxidants (Bolling et al. 2011), and that some nuts, in particular, Brazil nuts, are high in

370 selenium (Thomson et al. 2008). Interestingly, among those who responded with agreement or

371 disagreement to the perception statements, overall there was greatest agreement that 'some of

372 them are high in selenium". This tends to indicate that the message that Brazil nuts are high in

373 selenium is reaching some people. Given that NZ soils are low in selenium and the risk of

374 inadequate intake of selenium has been estimated at 45\% (University of Otago and Ministry of

375 Health 2011), Brazil nuts offer a useful source of this nutrient.

376 The strengths of the study include the recruitment of large national samples and the rigorous

377 survey method using a mixed-mode approach using both an online and paper mail version of the

378 questionnaire to improve response rates.

379 There are also a number of limitations to be considered when interpreting the data. The cross-

380 sectional nature of the study allows for generation of hypotheses for future research, but means

381 that causal inferences cannot be drawn. The surveys were self-administered, and it is possible

382 that some respondents did not correctly interpret all questions. However, careful development

383 and pre-testing of the questionnaires was undertaken to address this. Response rates were 44\%

384 for the general population and 53\% for the health professionals. Although these are comparable

385 to other mail surveys in Australasia (Lee et al. 2005; Timperio et al. 2000), it is possible

386 responders and non-responders differed. While this may influence means, medians, and

387 percentages; there are no clear reasons why the observed associations would differ between

388 responders and non-responders. The results may not be generalisable to countries with healthcare

389 systems those differ from that seen in NZ. Also, we cannot link the perceptions/beliefs of health

390 professionals with their patients due to the design of the study. Linked data would help to 
391 determine whether attitudes can be transmitted between these groups. This would provide useful

392 information on whether an intervention, which positively influences health professionals' views

393 on nuts could be expected to influence the views of their patients.

394

\section{Conclusions}

396 It is concerning that so few of the general public report they have received advice from health 397 professionals to consume more nuts, especially given their apparent responsiveness to such 398 advice. Interestingly, both the general public and health professionals consider nuts to be healthy, 399 which may mean that they would be willing to increase intake and advice to increase nuts 400 respectively, if some of the deterrents for eating nuts are addressed. These deterrents included 401 cost, weight gain, and causing one to eat too much fat. We also identified some important 402 motivators to increase nut consumption such as improving health, increasing nutrients in the diet, 403 helping get the right balance of fat, and if they were more affordable. Given that over half of the 404 participants would eat more nuts if advised to by their doctor or dietitian, health professionals 405 should use these potential facilitators to promote regular nut consumption. In addition, these 406 factors should also be addressed in public health messages to encourage regular nut consumption 407 among the public.

408

409

\section{Acknowledgments}

411 The authors would like to thank the participants for their commitment and enthusiasm in 412 participating in this study.

413

\section{References}

415 Afshin A, Micha R, Khatibzadeh S, and Mozaffarian D. 2014. Consumption of nuts and legumes 416 and risk of incident ischemic heart disease, stroke, and diabetes: a systematic review and meta-analysis. Am J Clin Nutr 100:278-288. 10.3945/ajcn.113.076901

418 Alasalvar C, and Bolling BW. 2015. Review of nut phytochemicals, fat-soluble bioactives, 419 antioxidant components and health effects. Br J Nutr 113 Suppl 2:S68-78. $10.1017 / \mathrm{S} 0007114514003729$ 
421 Alper CM, and Mattes RD. 2002. Effects of chronic peanut consumption on energy balance and

422

423

424

425

426

427

428

429

430

431

432

433

434

435

436

437

438

439

440

441

442

443

444

445

446

447

448

449

450

451 hedonics. Int J Obes Relat Metab Disord 26:1129-1137.

Aune D, Keum N, Giovannucci E, Fadnes LT, Boffetta P, Greenwood DC, Tonstad S, Vatten LJ, Riboli E, and Norat T. 2016. Nut consumption and risk of cardiovascular disease, total cancer, all-cause and cause-specific mortality: a systematic review and dose-response meta-analysis of prospective studies. BMC Med 14:207. 10.1186/s12916-016-0730-3

Bao Y, Han J, Hu FB, Giovannucci EL, Stampfer MJ, Willett WC, and Fuchs CS. 2013a. Association of nut consumption with total and cause-specific mortality. $N$ Engl J Med 369:2001-2011. 10.1056/NEJMoa1307352

Bao Y, Hu FB, Giovannucci EL, Wolpin BM, Stampfer MJ, Willett WC, and Fuchs CS. 2013 b. Nut consumption and risk of pancreatic cancer in women. Br J Cancer 109:2911-2916. 10.1038/bjc. 2013.665

Bes-Rastrollo M, Sabate J, Gomez-Gracia E, Alonso A, Martinez JA, and Martinez-Gonzalez MA. 2007. Nut consumption and weight gain in a Mediterranean cohort: the SUN Study. Obesity 15:107-116.

Bes-Rastrollo M, Wedick NM, Martinez-Gonzalez MA, Li TY, Sampson L, and Hu FB. 2009. Prospective study of nut consumption, long-term weight change, and obesity risk in women. Am J Clin Nutr 89:1913-1919. 10.3945/ajcn.2008.27276

Bolling BW, Chen CY, McKay DL, and Blumberg JB. 2011. Tree nut phytochemicals: composition, antioxidant capacity, bioactivity, impact factors. A systematic review of almonds, Brazils, cashews, hazelnuts, macadamias, pecans, pine nuts, pistachios and walnuts. Nutr Res Rev 24:244-275. 10.1017/S095442241100014X

Brennan AM, Sweeney LL, Liu X, and Mantzoros CS. 2010. Walnut consumption increases satiation but has no effect on insulin resistance or the metabolic profile over a 4-day period. Obesity 18:1176-1182.

Brown RC, Tey SL, Gray AR, Chisholm A, Smith C, Fleming E, Blakey C, and Parnell W. 2014. Patterns and predictors of nut consumption: results from the 2008/09 New Zealand Adult Nutrition Survey. Br J Nutr 112:2028-2040. 10.1017/S0007114514003158

Brown RC, Yong LC, Gray AR, Tey SL, Chisholm A, and Leong SL. 2017. Perceptions and Knowledge of Nuts amongst Health Professionals in New Zealand. Nutrients 9:220, doi:210.3390/nu9030220. 10.3390/nu9030220 
452 Brufau G, Boatella J, and Rafecas M. 2006. Nuts: source of energy and macronutrients. $\mathrm{Br} J$ $453 \quad$ Nutr 96:S24-S28. doi:10.1017/BJN20061860

454 Claesson A-L, Holm G, Ernersson Ã, Lindström T, and Nystrom FH. 2009. Two weeks of 455

456 overfeeding with candy, but not peanuts, increases insulin levels and body weight. Scand J Clin Lab Invest 69:598-605. doi:10.1080/00365510902912754

457 Coelho SB, de Sales RL, Iyer SS, Bressan J, Costa NMB, Lokko P, and Mattes R. 2006. Effects 458 459 of peanut oil load on energy expenditure, body composition, lipid profile, and appetite in lean and overweight adults. Nutrition 22:585-592.

460

Dillman D. 2011. Mail and internet surveys: The tailored design method - 2007 update with new 461 internet, visual, and mixed-mode guide. Hoboken: John Wiley \& Sons Inc.

462 Electoral Commission. 2014. http://www.elections.org.nz/research-statistics/enrolment463 statistics-electorate (accessed October, 2014.)

464 Ellis PR, Kendall CWC, Ren Y, Parker C, Pacy JF, Waldron KW, and Jenkins DJA. 2004. Role 465 466 467 468 469 470 471 472 473 of cell walls in the bioaccessibility of lipids in almond seeds. Am J Clin Nutr 80:604-613.

Fadelu T, Zhang S, Niedzwiecki D, Ye X, Saltz LB, Mayer RJ, Mowat RB, Whittom R, Hantel A, Benson AB, Atienza DM, Messino M, Kindler HL, Venook A, Ogino S, Ng K, Wu K, Willett W, Giovannucci E, Meyerhardt J, Bao Y, and Fuchs CS. 2018. Nut Consumption and Survival in Patients With Stage III Colon Cancer: Results From CALGB 89803 (Alliance). J Clin Oncol 36:1112-1120. 10.1200/JCO.2017.75.5413

Flores-Mateo G, Rojas-Rueda D, Basora J, Ros E, and Salas-Salvadó J. 2013. Nut intake and adiposity: meta-analysis of clinical trials. Am J Clin Nutr 97:1346-1355. 10.3945/ajcn.111.031484

Fraser GE, Bennett HW, Jaceldo KB, and Sabate J. 2002. Effect on body weight of a free 76 kilojoule (320 calorie) daily supplement of almonds for six months. J Am Coll Nutr 21:275-283.

Gebauer SK, Novotny JA, Bornhorst GM, and Baer DJ. 2016. Food processing and structure impact the metabolizable energy of almonds. Food Funct 7:4231-4238.

480

Grosso G, and Estruch R. 2016. Nut consumption and age-related disease. Maturitas 84:11-16. 481 10.1016/j.maturitas.2015.10.014 
482 Grosso G, Yang J, Marventano S, Micek A, Galvano F, and Kales S. 2015. Nut consumption and 483 all-cause, cardiovascular, and cancer mortality risk: a systematic review and meta-

484

485

486

487

488

489

490

491

492

493

494

495

496

497

498

499

500

501

502

503

504

505

506

507

508

509

510

511 analysis of epidemiologic studies. Am J Clin Nutr 101:783-793. doi: 10.3945/ajen.114.099515

Grundy M, Grassby T, Mandalari G, Waldron K, PJ B, Berry S, and Ellis P. 2015. Effect of mastication on lipid bioaccessibility of almonds in a randomized human study and its implications for digestion kinetics, metabolizable energy, and postprandial lipemia. Am J Clin Nutr 101:25-33. doi:10.3945/ajen.114.088328

Grundy MM, Lapsley K, and Ellis PR. 2016. A review of the impact of processing on nutrient bioaccessibility and digestion of almonds. 51:1937-1946. 10.1111/ijfs.13192

Guasch-Ferre M, Liu X, Malik VS, Sun Q, Willett WC, Manson JE, Rexrode KM, Li Y, Hu FB, and Bhupathiraju SN. 2017. Nut Consumption and Risk of Cardiovascular Disease. J Am Coll Cardiol 70:2519-2532. 10.1016/j.jacc.2017.09.035

Hashemian M, Murphy G, Etemadi A, Dawsey SM, Liao LM, and Abnet CC. 2017. Nut and peanut butter consumption and the risk of esophageal and gastric cancer subtypes. $\mathrm{Am} \mathrm{J}$ Clin Nutr 106:858-864. 10.3945/ajcn.117.159467

Hollis J, and Mattes R. 2007. Effect of chronic consumption of almonds on body weight in healthy humans. Br J Nutr 98:651-656. doi:10.1017/S0007114507734608

Hshieh TT, Petrone AB, Gaziano JM, and Djousse L. 2015. Nut consumption and risk of mortality in the Physicians' Health Study. Am J Clin Nutr 101:407-412.

\subsection{5/ajen.114.099846}

Jenab M, Sabate J, Slimani N, Ferrari P, Mazuir M, Casagrande C, Deharveng G, Tyonneland A, Olsen A, Overvad K, Boutron-Ruault M-C, Clavel-Chapelon F, Boeing H, Weikert C, Linseisen J, Rohrmann S, Trichopoulou A, Naska A, Palli D, Sacerdote C, Tumino R, Mattiello A, Pala V, Bueno-de-Mesquita HB, Ock MC, Peeters PH, Engeset D, Skeie G, Jakszyn P, Ardanaz E, Quiros JR, Chirlaque MD, Martinez C, Amiano P, Berglund G, Palmqvist R, van Guelpen B, Bingham S, Key T, and Riboli E. 2006. Consumption and portion sizes of tree nuts, peanuts and seeds in the European Prospective Investigation into Cancer and Nutrition (EPIC) cohorts from 10 European countries. Br J Nutr 96:S12S23. doi:10.1017/BJN20061859 
512 Jiang R, Manson JE, Stampfer MJ, Liu S, Willett WC, and Hu FB. 2002. Nut and peanut butter 513 consumption and risk of type 2 diabetes in women. JAMA 288:2554-2560.

514 Katsiardanis K, Diamantaras AA, Dessypris N, Michelakos T, Anastasiou A, Katsiardani KP,

515

516

517

518

519

520

521

522

523

524

525

526

527

528

529

530

531

532

533

534

535

536

537

538

539

540 Kanavidis P, Papadopoulos FC, Stefanadis C, Panagiotakos DB, and Petridou ET. 2013. Cognitive impairment and dietary habits among elders: the Velestino Study. J Med Food 16:343-350. 10.1089/jmf.2012.0225

Kris-Etherton PM, Yu-Poth S, Sabate J, Ratcliffe HE, Zhao G, and Etherton TD. 1999. Nuts and their bioactive constituents: effects on serum lipids and other factors that affect disease risk. Am J Clin Nutr 70:S504-S511.

Lee C, Dobson AJ, Brown WJ, Bryson L, Byles J, Warner-Smith P, and Young AF. 2005. Cohort Profile: the Australian Longitudinal Study on Women's Health. Int J Epidemiol 34:987-991. 10.1093/ije/dyi098

Lee J, Shin A, Oh JH, and Kim J. 2018. The relationship between nut intake and risk of colorectal cancer: a case control study. Nutr J 17:37. 10.1186/s12937-018-0345-y

Lee JT, Lai GY, Liao LM, Subar AF, Bertazzi PA, Pesatori AC, Freedman ND, Landi MT, and Lam TK. 2017. Nut Consumption and Lung Cancer Risk: Results from Two Large Observational Studies. Cancer Epidemiol Biomarkers Prev 26:826-836. 10.1158/10559965.EPI-16-0806

Li TY, Brennan AM, Wedick NM, Mantzoros C, Rifai N, and Hu FB. 2009. Regular consumption of nuts is associated with a lower risk of cardiovascular disease in women with type 2 diabetes. J Nutr 139:1333-1338. 10.3945/jn.108.103622

Luo C, Zhang Y, Ding YS, Shan ZL, Chen SJ, Yu M, Hu FB, and Liu LG. 2014. Nut consumption and risk of type 2 diabetes, cardiovascular disease, and all-cause mortality: a systematic review and meta-analysis. Am J Clin Nutr 100:256-269. Doi 10.3945/Ajcn.113.076109

Luu HN, Blot WJ, Xiang YB, Cai H, Hargreaves MK, Li H, Yang G, Signorello L, Gao YT, Zheng W, and Shu XO. 2015. Prospective evaluation of the association of nut/peanut consumption with total and cause-specific mortality. JAMA Intern Med 175:755-766. 10.1001/jamainternmed.2014.8347 
541 Martinez-Gonzalez MA, and Bes-Rastrollo M. 2011. Nut consumption, weight gain and obesity: $542 \quad$ epidemiological evidence. Nutr Metab Cardiovasc Dis 21:S40-S45.

$543 \quad$ 10.1016/j.numecd.2010.11.005

544 Mattes RD. 2008. The energetics of nut consumption. Asia Pac J Clin Nutr 17:337-339.

545 Mattes RD, Kris-Etherton PM, and Foster GD. 2008. Impact of peanuts and tree nuts on body

$546 \quad$ weight and healthy weight loss in adults. J Nutr 138:S1741-S1745.

547 McKiernan F, Lokko P, Kuevi A, Sales RL, Costa NM, Bressan J, Alfenas RC, and Mattes RD. 548 2010. Effects of peanut processing on body weight and fasting plasma lipids. Br J Nutr $549 \quad 104: 418-426$.

550 Mozaffarian D, Hao T, Rimm EB, Willett WC, and Hu FB. 2011. Changes in diet and lifestyle 551

552 and long-term weight gain in women and men. N Engl J Med 364:2392-2404.

553 Musa-Veloso K, Paulionis L, Poon T, and Lee HY. 2016. The effects of almond consumption on 554

555 fasting blood lipid levels: a systematic review and meta-analysis of randomised controlled trials. J Nutr Sci 5:e34. 10.1017/jns.2016.19

557

Nash SD, and Nash DT. 2008. Nuts as part of a healthy cardiovascular diet. Curr Atheroscler

558 Rep 10:529-535.

Novotny JA, Gebauer SK, and Baer DJ. 2012. Discrepancy between the Atwater factor predicted 559 560 and empirically measured energy values of almonds in human diets. Am J Clin Nutr

561 96:296-301. 10.3945/ajcn.112.035782

O'Neil CE, Keast DR, Fulgoni VL, and Nicklas TA. 2010. Tree nut consumption improves nutrient intake and diet quality in US adults: an analysis of National Health and Nutrition Examination Survey (NHANES) 1999-2004. Asia Pac J Clin Nutr 19:142-150.

565

O'Neil CE, Keast DR, Nicklas TA, and Fulgoni VL. 2012. Out-of-hand nut consumption is 566 associated with improved nutrient intake and health risk markers in US children and adults: National Health and Nutrition Examination Survey 1999-2004. Nutr Res 32:185-

O'Neil CE, Nicklas TA, and Fulgoni VL. 2015. Tree nut consumption is associated with better nutrient adequacy and diet quality in adults: National Health and Nutrition Examination Survey 2005-2010. Nutrients 7:595-607. 10.3390/nu7010595 
571 Pawlak R, Colby S, and Herring J. 2009. Beliefs, benefits, barriers, attitude, intake and

572 knowledge about peanuts and tree nuts among WIC participants in eastern North

573 Carolina. Nutr Res Pract 3:220-225. 10.4162/nrp.2009.3.3.220

574 Pawlak R, London HA, Colby SE, Wall-Bassett E, and Sira N. 2012. Perception of nut intake

575 among individuals with or at risk for heart disease and/or diabetes. J Behav Health 1:185-

576188.

577 Ros E. 2010. Health benefits of nut consumption. Nutrients 2:652-682.

578 Ros E, Tapsell LC, and Sabate J. 2010. Nuts and berries for heart health. Curr Atheroscler Rep

579 12:397-406. $10.1007 / \mathrm{s} 11883-010-0132-5$

580 Sabate J, Cordero-MacIntyre Z, Siapco G, Torabian S, and Haddad E. 2005. Does regular walnut 581 consumption lead to weight gain? Br J Nutr 94:859-864. doi:10.1079/BJN20051567

582 Sabate J, Oda K, and Ros E. 2010. Nut consumption and blood lipid levels: a pooled analysis of 58325 intervention trials. Arch Intern Med 170:821-827. 10.1001/archinternmed.2010.79

584 Salas-Salvado J, Casas-Agustench P, and Salas-Huetos A. 2011. Cultural and historical aspects

585 of Mediterranean nuts with emphasis on their attributed healthy and nutritional

586 properties. Nutr Metab Cardiovasc Dis 21:S1-S6. Doi 10.1016/J.Numecd.2010.10.013

587 Samieri C, Okereke OI, E ED, and Grodstein F. 2013. Long-term adherence to the

588 Mediterranean diet is associated with overall cognitive status, but not cognitive decline,

589 in women. J Nutr 143:493-499. 10.3945/jn.112.169896

590 Spiller GA, Miller A, Olivera K, Reynolds J, Miller B, Morse SJ, Dewell A, and Farquhar JW.

591 2003. Effects of plant-based diets high in raw or roasted almonds, or roasted almond

592 butter on serum lipoproteins in humans. J Am Coll Nutr 22:195-200.

593 Tan SY, and Mattes RD. 2013. Appetitive, dietary and health effects of almonds consumed with

594 meals or as snacks: a randomized, controlled trial. Eur J Clin Nutr 67:1205-1214.

$595 \quad 10.1038 /$ ejcn.2013.184

596 Tey S, Brown R, and Chisholm A. 2012. Nuts and heart health. National Heart Foundation of

597 New Zealand evidence-based position statement on the relationship of nuts to heart

598 health. Auckland, New Zealand: National Heart Foundation of New Zealand.

599 Tey SL, Brown R, Gray A, Chisholm A, and Delahunty C. 2011. Nuts improve diet quality 600 compared to other energy-dense snacks while maintaining body weight. J Nutr Metab $601 \quad 2011: 357350$. 
602 Thomson CD, Chisholm A, McLachlan SK, and Campbell JM. 2008. Brazil nuts: an effective 603 way to improve selenium status. Am J Clin Nutr 87:379-384.

604 Timperio A, Cameron-Smith D, Burns C, Salmon J, and Crawford D. 2000. Physical activity 605 beliefs and behaviours among adults attempting weight control. Int J Obes Relat Metab $606 \quad$ Disord 24:81-87.

607 University of Otago and Ministry of Health. 2011. A focus on nutrition: key findings of the 608 2008/09 New Zealand Adult Nutrition Survey. Wellington: Ministry of Health.

609 US Food and Drug Administration. 2003. Qualified health claims: letter of enforcement 610 discretion-nuts and coronary heart disease (Docket No 02P-0505). Available at http://www.fda.gov/Food/IngredientsPackagingLabeling/LabelingNutrition/ucm072926.h $\underline{\text { tm }}$ (accessed 2 September 2013).

613

Valls-Pedret C, Lamuela-Raventos RM, Medina-Remon A, Quintana M, Corella D, Pinto X, 614 Martinez-Gonzalez MA, Estruch R, and Ros E. 2012. Polyphenol-rich foods in the Mediterranean diet are associated with better cognitive function in elderly subjects at high cardiovascular risk. J Alzheimers Dis 29:773-782 . 10.3233/JAD-2012-111799

van den Brandt PA, and Nieuwenhuis L. 2018. Tree nut, peanut, and peanut butter intake and 618 risk of postmenopausal breast cancer: The Netherlands Cohort Study. Cancer Causes Control 29:63-75. 10.1007/s10552-017-0979-7

621

622

623

Wengreen H, Munger RG, Cutler A, Quach A, Bowles A, Corcoran C, Tschanz JT, Norton MC, 624 625 626

van den Brandt PA, and Schouten LJ. 2015. Relationship of tree nut, peanut and peanut butter intake with total and cause-specific mortality: a cohort study and meta-analysis. Int $J$ Epidemiol 44:1038-1049. 10.1093/ije/dyv039

Wu L, Wang Z, Zhu J, Murad AL, Prokop LJ, and Murad MH. 2015. Nut consumption and risk 629 of cancer and type 2 diabetes: a systematic review and meta-analysis. Nutr Rev 73:409425. 10.1093/nutrit/nuv006 
631 Yong LC, Gray AR, Chisholm A, Leong SL, Tey SL, and Brown RC. 2017. Barriers to and 632 facilitators and perceptions of nut consumption among the general population in New 633 Zealand. Public Health Nutr 20:3166-3182. 10.1017/S1368980017002464

634 Zhou DH, Yu HB, He F, Reilly KH, Zliang JL, Li SS, Zhang T, Wang BZ, Ding YL, and Xi B.

635 2014. Nut consumption in relation to cardiovascular disease risk and type 2 diabetes: a

636 systematic review and meta-analysis of prospective studies. Am J Clin Nutr 100:270-277.

637 Doi $10.3945 /$ Ajcn.113.079152

638 
Table $\mathbf{1}$ (on next page)

Characteristics of survey participants. 
Table 1. Characteristics of survey participants

\begin{tabular}{|c|c|c|c|c|c|}
\hline Demographic & Dietitians & General Practitioners & Practice Nurses & $\begin{array}{c}\text { General } \\
\text { Population }\end{array}$ & $\begin{array}{c}\text { General Population } \\
\text { non-health } \\
\text { professionals } \\
\end{array}$ \\
\hline $\mathrm{n}$ & 318 & 292 & 149 & 710 & 668 \\
\hline Female $\%(n)$ & $96.5(307)$ & $57.2(167)$ & $96.0(143)$ & $56.5(401)$ & $54.6(365)$ \\
\hline Age, years & $42.5(12.0)$ & $50.6(8.4)$ & $50.9(10.3)$ & $52.9(16.9)$ & $53.1(17.1)$ \\
\hline \multicolumn{6}{|l|}{ Ethnicity \% (n) } \\
\hline European & $87.1(277)$ & $82.2(240)$ & $88.6(132)$ & $70.3(499)$ & $69.8(466)$ \\
\hline Māori & $5.7(18)$ & $2.7(8)$ & $4.0(6)$ & $12.4(88)$ & $12.7(85)$ \\
\hline Asian & $5.7(18)$ & $10.3(30)$ & $4.7(7)$ & $6.2(44)$ & $6.1(41)$ \\
\hline Other & $1.6(5)$ & $4.8(14)$ & $2.7(4)$ & $11.1(79)$ & $11.4(76)$ \\
\hline \multicolumn{6}{|l|}{ Employment status \% (n) } \\
\hline Employed & $100(318)$ & $100(292)$ & $100(149)$ & $62.9(437)$ & $61.9(404)$ \\
\hline Not enployed & $0.0(0)$ & $0.0(0)$ & $0.0(0)$ & $37.1(258)$ & $38.1(249)$ \\
\hline \multicolumn{6}{|l|}{ Highest level of education $\%(n)$} \\
\hline Less than secondary & $0.0(0)$ & $0.0(0)$ & $0.0(0)$ & $2.2(15)$ & $2.3(15)$ \\
\hline Secondary & $0.0(0)$ & $0.0(0)$ & $0.0(0)$ & $36.6(252)$ & $38.4(248)$ \\
\hline Post-secondary & $100(318)$ & $100(292)$ & $100(149)$ & $61.2(421)$ & $59.3(383)$ \\
\hline $\begin{array}{l}\text { No. of years as a registered practitioner } \\
\text { median (IQR) }\end{array}$ & $13.0(20.0)$ & $20.0(15.0)$ & $25.0(17.5)$ & - & - \\
\hline
\end{tabular}

All values are means (SD) unless otherwise specified 


\section{Table 2 (on next page)}

The percentage of general population participants previously receiving advice from a health professional regarding nut consumption $(n=710)$. 
1 Table 2. The percentage of general population participants previously receiving advice from a health professional regarding nut consumption $(n=710)$.

3

\begin{tabular}{|c|c|c|c|c|}
\hline Previous advice received & Dietitian & $\begin{array}{c}\text { General } \\
\text { practitioner } \\
\%(\mathrm{n})\end{array}$ & $\begin{array}{l}\text { Practice } \\
\text { nurse }\end{array}$ & $\begin{array}{l}\text { Any of these } \\
\text { professionals }\end{array}$ \\
\hline Advised to eat more nuts or nut butters by & $3.8(27)$ & $2.8(20)$ & $1.1(8)$ & $7.2(51)$ \\
\hline Advised to eat less nuts or nut butters by & $0.7(5)$ & $1.7(12)$ & $0.3(2)$ & $2.5(18)$ \\
\hline Advised to maintain level of nut consumption by & $0.7(5)$ & $1.1(8)$ & $0.6(4)$ & $2.1(15)$ \\
\hline Do not discuss nut consumption with dietitian, GP, or practice nurse & & & & $83.9(596)$ \\
\hline Have not seen a dietitian, GP, or practice nurse in the last 5 years & & - & & $6.6(47)$ \\
\hline
\end{tabular}




\section{Table 3(on next page)}

Conditional motivation to eat more nuts or nut butters among the general population $(n=710)$. 
Table 3. Conditional motivation to eat more nuts or nut butters among the general population $(\mathrm{n}=710)$

\begin{tabular}{|c|c|c|c|c|c|c|c|}
\hline \multirow[t]{2}{*}{ Conditional motivation } & $\begin{array}{c}\text { Strongly } \\
\text { agree }\end{array}$ & Agree & $\begin{array}{c}\text { Neither agree } \\
\text { nor disagree }\end{array}$ & Disagree & $\begin{array}{l}\text { Strongly } \\
\text { disagree }\end{array}$ & $\begin{array}{c}\text { Mean } \\
(95 \% \mathrm{CI})^{*}\end{array}$ & $\begin{array}{l}\text { Do not } \\
\text { know }\end{array}$ \\
\hline & \multicolumn{6}{|c|}{$\%(\mathrm{n})$} & \\
\hline Eating them would help me be healthier & $15.0(100)$ & $51.7(345)$ & $19.8(132)$ & $5.7(38)$ & $0.6(4)$ & $2.2(2.1,2.3)$ & $7.2(48)$ \\
\hline They were more affordable & $26.5(177)$ & $33.4(223)$ & $21.3(142)$ & $11.5(77)$ & $2.0(13)$ & $2.3(2.2,2.3)$ & $5.3(35)$ \\
\hline Eating them would help me get more nutrients & $11.9(79)$ & $47.1(312)$ & $24.0(159)$ & $6.2(41)$ & $0.6(4)$ & $2.3(2.2,2.4)$ & $10.1(67)$ \\
\hline Eating them would help me get the right balance of good fats & $12.1(80)$ & $46.2(306)$ & $21.6(143)$ & $7.1(47)$ & $0.6(4)$ & $2.3(2.2,2.4)$ & $12.5(83)$ \\
\hline A dietitian advised me to & $10.5(68)$ & $43.5(282)$ & $22.5(146)$ & $10.8(70)$ & $2.2(14)$ & $2.4(2.4,2.5)$ & $10.6(69)$ \\
\hline My doctor advised me to & $10.3(67)$ & $42.6(277)$ & $22.3(145)$ & $12.0(78)$ & $2.2(14)$ & $2.5(2.4,2.6)$ & $10.6(69)$ \\
\hline Eating them would help me get the fibre I need & $9.6(64)$ & $43.2(287)$ & $26.8(178)$ & $8.9(59)$ & $1.1(7)$ & $2.4(2.3,2.5)$ & $10.5(70)$ \\
\hline Eating them would help me feel better & $10.0(66)$ & $40.5(268)$ & $30.4(201)$ & $9.4(62)$ & $1.1(7)$ & $2.5(2.4,2.5)$ & $8.6(57)$ \\
\hline Eating them would give me the energy/calories I need & $9.2(61)$ & $39.1(260)$ & $31.3(208)$ & $9.2(61)$ & $2.0(13)$ & $2.5(2.4,2.6)$ & $9.3(62)$ \\
\hline I had more knowledge of recipes involving them & $5.5(36)$ & $34.6(227)$ & $30.8(202)$ & $16.8(110)$ & $3.1(20)$ & $2.7(2.7,2.8)$ & $9.3(61)$ \\
\hline They were lower in fat & $8.7(57)$ & $30.2(198)$ & $31.0(203)$ & $17.1(112)$ & $1.7(11)$ & $2.7(2.6,2.8)$ & $11.3(74)$ \\
\hline They were lower in calories & $8.3(54)$ & $27.5(179)$ & $32.4(211)$ & $18.7(122)$ & $1.5(10)$ & $2.7(2.7,2.8)$ & $11.7(76)$ \\
\hline They were more available where I go shopping & $4.7(31)$ & $18.8(123)$ & $37.2(244)$ & $26.1(171)$ & $4.7(31)$ & $3.1(3.0,3.2)$ & $8.5(56)$ \\
\hline They had more flavor & $3.4(22)$ & $14.6(95)$ & $33.5(219)$ & $33.5(219)$ & $8.0(52)$ & $3.3(3.2,3.4)$ & $7.0(46)$ \\
\hline
\end{tabular}

3 values are \% (n) except for means and CIs

$4 * 1=$ strongly agree, $2=$ agree, $3=$ neither agree nor disagree, $4=$ disagree, $5=$ strongly disagree 


\section{Table 4 (on next page)}

Conditional deterrents to eating nuts or nut butters among the general public $(n=710)$. 
Table 4. Conditional deterrents to eating nuts or nut butters among the general public $(n=710)$

2

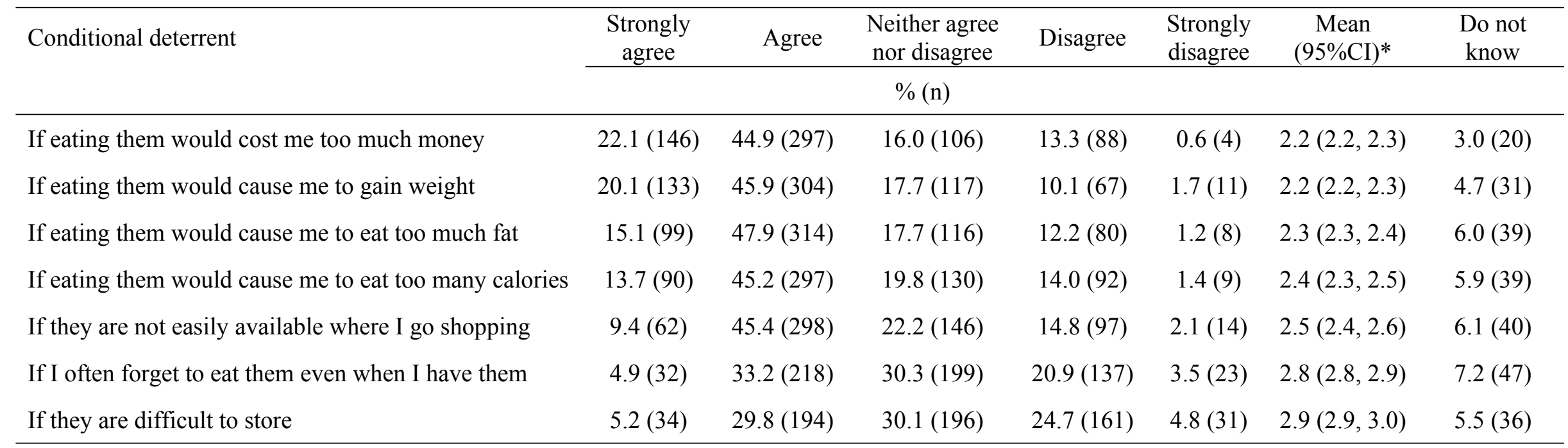

3 values are \% (n) except for means and CIs

$4 * 1=$ strongly agree, $2=$ agree, $3=$ neither agree nor disagree, $4=$ disagree, $5=$ strongly disagree 


\section{Table 5 (on next page)}

Comparison of beliefs and perceptions of nuts between the general public and health professionals. 
1 Table 5. Comparison of beliefs and perceptions of nuts between the general public and health professionals.

\begin{tabular}{|c|c|c|c|c|c|c|}
\hline Beliefs and perceptions & $\begin{array}{c}\text { Dietitians } \\
(n=318)\end{array}$ & $\begin{array}{c}\text { General } \\
\text { Practitioners } \\
(\mathrm{n}=292)\end{array}$ & $\begin{array}{l}\text { Practice } \\
\text { Nurses } \\
(\mathrm{n}=149)\end{array}$ & $\begin{array}{c}\text { General } \\
\text { Population } \\
\text { Non-health } \\
\text { Professionals } \\
(\mathrm{n}=668) \\
\end{array}$ & $\begin{array}{l}\text { Unadjusted } \\
\text { P-value }\end{array}$ & $\begin{array}{c}\text { *Adjusted } \\
\text { P-value }\end{array}$ \\
\hline Some of them are high in selenium ${ }^{1}$ & $1.6(1.5,1.6)^{\mathrm{a}}$ & $1.9(1.8,2.0)^{\mathrm{b}}$ & $1.8(1.7,1.9)^{\mathrm{b}}$ & $2.2(2.2,2.3)^{\mathrm{c}}$ & $<0.001$ & $<0.001$ \\
\hline They are low in energy/calories ${ }^{2}$ & $4.5(4.4,4.5)^{\mathrm{a}}$ & $4.4(4.3,4.5)^{\mathrm{a}}$ & $4.0(3.8,4.2)^{\mathrm{b}}$ & $3.5(3.4,3.6)^{\mathrm{c}}$ & $<0.001$ & $<0.001$ \\
\hline They are healthy ${ }^{1}$ & $1.7(1.6,1.8)^{\mathrm{a}}$ & $2.0(1.9,2.1)^{\mathrm{bc}}$ & $1.9(1.8,2.0)^{\mathrm{b}}$ & $2.1(2.0,2.2)^{\mathrm{c}}$ & $<0.001$ & $<0.001$ \\
\hline They are high in protein ${ }^{1}$ & $1.9(1.8,2.0)^{\mathrm{a}}$ & $2.0(1.9,2.1)^{\mathrm{a}}$ & $1.8(1.8,1.9)^{\mathrm{a}}$ & $2.1(2.0,2.1)^{\mathrm{b}}$ & 0.001 & 0.013 \\
\hline They are filling ${ }^{1}$ & $1.9(1.9,2.0)^{\mathrm{a}}$ & $2.0(1.9,2.1)^{\mathrm{ab}}$ & $2.1(2.0,2.2)^{\mathrm{bc}}$ & $2.2(2.2,2.3)^{\mathrm{c}}$ & $<0.001$ & $<0.001$ \\
\hline They are high in fat ${ }^{1}$ & $1.7(1.6,1.8)^{\mathrm{a}}$ & $2.1(2.0,2.2)^{\mathrm{b}}$ & $2.1(2.0,2.3)^{\mathrm{b}}$ & $2.4(2.1,2.5)^{\mathrm{c}}$ & $<0.001$ & $<0.001$ \\
\hline They are low in vitamins \& minerals ${ }^{2}$ & $4.2(4.1,4.3)^{\mathrm{a}}$ & $4.1(4.0,4.2)^{\mathrm{a}}$ & $3.8(3.6,4.0)^{\mathrm{b}}$ & $3.5(3.4,3.6)^{\mathrm{c}}$ & $<0.001$ & $<0.001$ \\
\hline Eating them can increase people's risk of cardiovascular disease ${ }^{2}$ & $4.3(4.2,4.4)^{\mathrm{a}}$ & $3.8(3.7,3.9)^{\mathrm{b}}$ & $3.7(3.6,3.9)^{\mathrm{b}}$ & $3.4(3.3,3.5)^{\mathrm{c}}$ & $<0.001$ & $<0.001$ \\
\hline They are high in antioxidants ${ }^{1}$ & $2.1(2.1,2.2)^{\mathrm{a}}$ & $2.3(2.2,2.4)^{\mathrm{b}}$ & $2.3(2.1,2.4)^{\mathrm{b}}$ & $2.5(2.4,2.6)^{b}$ & $<0.001$ & $<0.001$ \\
\hline They are naturally high in salt/sodium ${ }^{2}$ & $4.3(4.2,4.3)^{\mathrm{a}}$ & $3.7(3.5,3.8)^{\mathrm{b}}$ & $3.6(3.4,3.7)^{\mathrm{b}}$ & $3.0(2.9,3.1)^{\mathrm{c}}$ & $<0.001$ & $<0.001$ \\
\hline They are low in fibre ${ }^{2}$ & $4.0(3.9,4.1)^{\mathrm{a}}$ & $3.6(3.4,3.7)^{\mathrm{b}}$ & $3.6(3.4,3.8)^{\mathrm{b}}$ & $3.4(3.3,3.5)^{\mathrm{b}}$ & $<0.001$ & $<0.001$ \\
\hline Eating them can increase people's total blood cholesterol ${ }^{2}$ & $4.0(3.9,4.1)^{\mathrm{a}}$ & $3.4(3.3,3.5)^{b}$ & $3.4(3.3,3.6)^{\mathrm{bc}}$ & $3.2(3.1,3.3)^{\mathrm{c}}$ & $<0.001$ & $<0.001$ \\
\hline Some of them are high in iron ${ }^{4}$ & $2.8(2.7,3.0)^{\mathrm{a}}$ & $2.7(2.5,2.8)^{\mathrm{a}}$ & $2.4(2.2,2.6)^{\mathrm{b}}$ & $2.3(2.3,2.4)^{\mathrm{b}}$ & $<0.001$ & $<0.001$ \\
\hline Eating them can help lower people's risk of diabetes ${ }^{3}$ & $2.6(2.6,2.7)$ & $2.7(2.6,2.8)$ & $2.7(2.5,2.9)$ & $2.8(2.7,2.9)$ & 0.186 & 0.096 \\
\hline Eating them will cause people to gain weight ${ }^{2}$ & $3.4(3.3,3.5)$ & $3.2(3.1,3.3)$ & $3.2(3.1,3.4)$ & $3.1(3.0,3.2)$ & 0.017 & 0.068 \\
\hline
\end{tabular}

Values are mens (95\% Confidonce Intervas)

P-values are determined using linear regression

*Adjusted for age, sex, ethnicity, education, employment

Values with different superscript letters are significantly different, $\mathrm{P}<0.05$

$1=$ strongly agree, $2=$ agree, $3=$ neither agree nor disagree, $4=$ disagree, $5=$ strongly disagree

Note some statements are supported by current evidence and some are worded in contradiction to current evidence

${ }^{1}$ Statements that are strongly supported by current evidence

${ }^{2}$ Statements that are strongly contradicted by current evidence

${ }^{3}$ Statements where current evidence is uncertain

${ }^{4}$ Some nuts such as pistachios, cashews and almonds contain useful ( $>4 \mathrm{mg}$ of non-haeme iron/100g) amounts of iron, but bioavailability and significance will

rely on other dietary factors 
Table 6(on next page)

Comparison of those who responded 'do not know" to perceptions of nuts between the general public and 3 groups of health professionals. 
1 Table 6. Comparison of those who responded 'do not know" to perceptions of nuts between the general public and 3 groups of health professionals.

\begin{tabular}{|c|c|c|c|c|c|}
\hline Beliefs and perceptions & $\begin{array}{c}\text { Dietitians } \\
(\mathrm{n}=318)\end{array}$ & $\begin{array}{c}\text { General } \\
\text { Practitioners } \\
(\mathrm{n}=292)\end{array}$ & $\begin{array}{l}\text { Practice } \\
\text { Nurses } \\
(n=149)\end{array}$ & $\begin{array}{c}\text { General } \\
\text { Population } \\
\text { Non-health } \\
\text { Professionals } \\
(\mathrm{n}=668) \\
\end{array}$ & P-value \\
\hline They are healthy ${ }^{1}$ & $0.0(0)^{\mathrm{a}}$ & $0.4(1)^{\mathrm{a}}$ & $0.0(0)^{\mathrm{a}}$ & $6.8(44)^{\mathrm{b}}$ & $<0.001$ \\
\hline They are filling ${ }^{1}$ & $0.0(0)^{\mathrm{a}}$ & $1.7(5)^{\mathrm{b}}$ & $0.7(1)^{\mathrm{ab}}$ & $8.8(55)^{\mathrm{c}}$ & $<0.001$ \\
\hline They are high in fat $1^{1}$ & $0.0(0)^{\mathrm{a}}$ & $0.7(2)^{\mathrm{ab}}$ & $1.4(2)^{\mathrm{b}}$ & $17.4(107)^{\mathrm{c}}$ & $<0.001$ \\
\hline They are high in protein ${ }^{1}$ & $0.0(0)^{\mathrm{a}}$ & $1.4(4)^{b}$ & $2.0(3)^{\mathrm{b}}$ & $17.8(110)^{\mathrm{c}}$ & $<0.001$ \\
\hline Eating them will cause people to gain weight $\mathrm{t}^{2}$ & $0.0(0)^{\mathrm{a}}$ & $1.0(3)^{\mathrm{ab}}$ & $1.3(2)^{\mathrm{b}}$ & $20.9(128)^{\mathrm{c}}$ & $<0.001$ \\
\hline They are low in energy/calories ${ }^{2}$ & $0.0(0)^{\mathrm{a}}$ & $0.7(2)^{\mathrm{a}}$ & $0.7(1)^{\mathrm{a}}$ & $22.7(139)^{\mathrm{b}}$ & $<0.001$ \\
\hline They are low in vitamins $\&$ minerals ${ }^{2}$ & $0.6(2)^{\mathrm{a}}$ & $4.2(12)^{\mathrm{b}}$ & $2.0(3)^{\mathrm{ab}}$ & $29.0(182)^{\mathrm{c}}$ & $<0.001$ \\
\hline They are low in fibre ${ }^{2}$ & $0.3(1)^{\mathrm{a}}$ & $6.3(18)^{\mathrm{b}}$ & $2.7(4)^{b}$ & $31.5(193)^{\mathrm{c}}$ & $<0.001$ \\
\hline They are naturally high in salt/sodium ${ }^{2}$ & $0.6(2)^{\mathrm{a}}$ & $10.4(30)^{b}$ & $6.0(9)^{\mathrm{b}}$ & $31.1(190)^{\mathrm{c}}$ & $<0.001$ \\
\hline $\begin{array}{l}\text { Eating them can increase people's risk of cardiovascular } \\
\text { disease }^{2}\end{array}$ & $1.3(4)^{\mathrm{a}}$ & $4.5(13)^{\mathrm{b}}$ & $4.0(6)^{\mathrm{ab}}$ & $39.2(240)^{\mathrm{c}}$ & $<0.001$ \\
\hline Eating them can increase people's total blood cholesterol ${ }^{2}$ & $2.2(7)^{\mathrm{a}}$ & $6.9(20)^{\mathrm{b}}$ & $6.0(9)^{\mathrm{b}}$ & $42.6(261)^{\mathrm{c}}$ & $<0.001$ \\
\hline They are high in antioxidants ${ }^{1}$ & $5.5(17)^{\mathrm{a}}$ & $17.8(51)^{\mathrm{b}}$ & $14.8(22)^{b}$ & $38.6(236)^{\mathrm{c}}$ & $<0.001$ \\
\hline Some of them are high in selenium ${ }^{1}$ & $2.2(7)^{\mathrm{a}}$ & $18.8(54)^{\mathrm{b}}$ & $18.4(27)^{\mathrm{b}}$ & $44.8(267)^{\mathrm{c}}$ & $<0.001$ \\
\hline Eating them can help lower people's risk of diabetes ${ }^{3}$ & $9.5(30)^{\mathrm{a}}$ & $16.3(47)^{\mathrm{b}}$ & $13.5(20)^{\mathrm{ab}}$ & $53.7(330)^{\mathrm{c}}$ & $<0.001$ \\
\hline Some of them are high in iron ${ }^{4}$ & $10.6(33)^{\mathrm{a}}$ & $25.0(72)^{\mathrm{b}}$ & $17.8(26)^{\mathrm{b}}$ & $41.7(252)^{\mathrm{c}}$ & $<0.001$ \\
\hline
\end{tabular}

Values are presented as \% (number)

P-values were determined using chi-squared test, values with different superscript letters are significantly different, $\mathrm{P}<0.05$

4 Note some statements are supported by current evidence and some are worded in contradiction to current evidence

$5 \quad{ }^{1}$ Statements that are strongly supported by current evidence

6 '2 Statements that are strongly contradicted by current evidence

$7 \quad{ }^{3}$ Statements where current evidence is uncertain 
$8{ }^{4}$ Some nuts such as pistachios, cashews and almonds contain useful ( $>4 \mathrm{mg}$ of non-haeme iron/100g) amounts of iron, but bioavailability and significance will rely on other dietary 9 factors 